\title{
Fascicular Tachycardia by ECG Finding
}

National Cancer Institute

\section{Source}

National Cancer Institute. Fascicular Tachycardia by ECG Finding. NCI Thesaurus. Code C71061.

An electrocardiographic finding of relatively short duration QRS complexes that originate from the region of the posterior fascicle (or occasionally the anterior fascicle) of the left bundle branch. 